\title{
Paromay thermal springs of Sakhalin Island: modern state and prospects for use
}

\author{
Rafael'V. Zharkov*1 \\ Dmitry N. Kozlov ${ }^{1}$ \\ Valeryi V. Ershov ${ }^{1}$ \\ Nadezhda S. Syrbu ${ }^{2}$ \\ Ol'ga A. Nikitenko' \\ Gennadyi V. Ustyugov ${ }^{1}$
}

\author{
${ }^{1}$ Institute of Marine Geology and Geophysics, FEB RAS, \\ Yuzhno-Sakhalinsk, Russia \\ ${ }^{2}$ V.I. Ilyichev Pacific Oceanological Institute, FEB RAS, Vladivostok, \\ Russia \\ *E-mail:rafael_zharkov@mail.ru
}

\begin{abstract}
Peферат PDF Rus
The paper presents the results of modern studies of physical and chemical features of littleknown Paromay thermal springs in the north of Sakhalin Island, obtained during field works in November 2018 and October 2019. There were no significant changes in the thermal spring physical and chemical features in comparison with the previous studies of 1951 and 1953. Several thermal springs with a temperature up to $32^{\circ} \mathrm{C}$ are on a small plot in the floodplain of the Paromay River. By chemical composition Paromay springs belong to fresh (mineralization up to $0.68 \mathrm{~g} / \mathrm{l}$ ), slightly alkaline ( $\mathrm{pH} 7.3-7.5$ ), hydrogen carbonate-chloride sodium waters. Gas composition of thermal springs mainly consists of nitrogen $(61.4 \%)$ and methane $(31.6 \%)$, which are not typical to other thermal springs of North Sakhalin, in which the methane dominates. The measurements of volumetric activity of subsoil radon-222 in the area of thermal springs do not reveal abnormal concentrations; values of OA $\mathrm{Rn} 58-83 \mathrm{~Bq} / \mathrm{m}^{3}$ are comparable to other manifestations of thermal and mineral waters of the island. Computed by complex geothermal meters ( $\mathrm{Na}-\mathrm{K}, \mathrm{K}-\mathrm{Mg}, \mathrm{Na}-\mathrm{Li}$, $\mathrm{Mg}-\mathrm{Li}, \mathrm{SiO}_{2}$ ) the temperatures of deep water reservoir are $30-40^{\circ} \mathrm{C}$, which corresponds to thermal spring formation depth of $1-1.5 \mathrm{~km}$. Paromay thermal waters can be used as drinking water and for balneological application.
\end{abstract}

\section{Keywords}

thermal waters, Paromay, geochemical features, Sakhalin Island

For citation: Zharkov R.V., Kozlov D.N., Ershov V.V., Syrbu N.S., Nikitenko O.A., Ustyugov G.V. Paromay thermal springs of Sakhalin Island: modern state and prospects for use. Geosystems of Transition Zones, 2019, vol. 3, no. 4, pp. 428-437. (In Russian) https://doi.org/10.30730/2541-8912.2019.3.4.428-437

Для цитирования: Жарков Р.В., Козлов Д.Н., Ершов В.В., Сырбу Н.С., Никитенко О.А., Устюгов Г.В. Паромайские термальные источники острова Сахалин: современное состояние и перспективы использования. Геосистемы переходных зон. 2019. Т. 3, № 4. С. 428-437. https://doi.org/10.30730/25418912.2019.3.4.428-437

\section{References}

1. ГОСТ Р 54316-2011. Воды минеральные природные питьевые. Общие технические условия. М.: Стандартинформ, 2011. $48 \mathrm{c}$.

2. Жарков Р.В. Современные физико-химические особенности термоминеральных вод Дагинского месторождения (о. Сахалин) // Мониторинг. Наука и технологии. 2018. № 4(37). С. 6-11. 
3. Жарков Р.В., Козлов Д.Н. Современные сведения о состоянии Агневских термальных источников (остров Сахалин) // Вестник ДВО РАН. 2017. № 1. С. 5-11.

4. Жарков Р.В., Козлов Д.Н., Веселов О.В., Ершов В.В., Сырбу Н.С., Никитенко О.А. Амурские термальные источники (остров Сахалин) // Успехи современного естествознания. 2018. № 11 (ч. 2). C. 317-322. https://doi.org/10.17513/use.36946

5. Зубков С.И. Радоновые предвестники землетрясений // Вулканология и сейсмология. 1981. № 6. С. $74-105$.

6. Иванов В.В. Курортные ресурсы Сахалина и перспективы их лечебного использования: отчет комплексного отряда Сахалинской экспедииии. М.: Центральный ин-т курортологии, 1954. 265 с.

7. Классификаиия минеральных вод и лечебных грязей для целей их сертификации: Методические указания № 2000/34 / А.Н. Разумов, В.Б. Адилов, О.Б. Давыдова и др. М.: РНЦ ВМиК, 2000. 150 с.

8. Левченко В.М., Макарова К.А. Минеральные источники и лечебные грязи Сахалина. НовоАлександровск: СФ АН СССР. 1953. 84 с. Инв. № 550-ф (фонды ИМГиГ ДВО РАН).

9. Ломтев В.Л., Патрикеев В.Н. Сейсмические признаки активных разломов Северного Сахалина = Lomtev V.L., Patrickeyev V.N. Seismic signatures indicators of North Sakhalin active faults // Геосистемы переходных зон = Geosystems of Transition Zones. 2017. T. 1, № 1. С. 37-48. doi:10.30730/2541-8912.2017.1.1.037-048

10. Макаров Е.О., Фирстов П.П., Костылев Д.В., Рылов Е.С., Дудченко И.П. Первые результаты мониторинга подпочвенного радона сетью пунктов, работающей в тестовом режиме, на юге острова Сахалин // Вестник КРАУНЦ. Физ.-мат. науки. 2018. № 5(25). С. 89-104. doi:10.18454/2079-66412018-25-5-89-104

11. Павлова В.Ю., Жарков Р.В. Результаты георадарных исследований на территории Дагинской гидротермальной системы (остров Сахалин) = Pavlova V.Yu., Zharkov R.V. GPR surveys of the discharge zone of the Daginsky hydrothermal system (Sakhalin Island) // Геосистемы переходных зон = Geosystems of Transition Zones. 2018. T. 2, № 4. C. 323-331. doi:10.30730/2541-8912.2018.2.4.323-331

12. Современная изученность гидротермоминеральных ресурсов Сахалина и Курильских островов и перспективы их использования в народном хозяйстве: геол. отчет за 1990-1991 гг. / исполн.: Т.С. Розорителева, В.Е. Прядко, Е.Л. Спалило. Южно-Сахалинск: Сахалингеология. 1991. 895 с. Инв. № 461852 (Росгеолфонд, Центральное фондохранилище).

13. Фирстов П. П., Макаров Е. О. Динамика подпочвенного радона на Камчатке. ПетропавловскКамчатский: КамГУ им. Витуса Беринга, 2018. 145 с.

14. Фирстов П.П., Макаров Е.О., Глухова И.П., Будилов Д.И., Исакевич Д.В. Поиск предвестниковых аномалий сильных землетрясений по данным мониторинга подпочвенных газов на ПетропавловскКамчатском геодинамическом полигоне = Firstov P.P., Makarov E.O., Glukhova I.P., Budilov D.I., Isakevich D.V. Search for predictive anomalies of strong earthquakes according to monitoring of subsoil gases at Petropavlovsk-Kamchatsky geodynamic test site // Геосистемы переходных зон = Gеоsystems of Transition Zones. 2018. T. 2, № 1. C. 16-32. doi:10.30730/2541-8912.2018.2.1.016-032

15. Цитенко Н.Д., Евстафьева В.И. Гидрогеологические факторы формирования и разрушения нефтяных и газовых залежей Сахалина: геол. отчет. Оха: ВНИГРИ, 1962. 307 с. Инв. № 1482-ф (фонды ИМГиГ ДВО РАН).

16. Челноков Г.А., Жарков Р.В., Брагин И.В., Веселов О.В., Харитонова Н.А., Шакиров Р.Б. Геохимические характеристики подземных флюидов южной части Центрально-Сахалинского разлома // Тихоокеанская геология. 2015. Т. 35, № 5. С. 81-95.

17. Челнокова Б.И., Гвозденко Т.А. Минеральные воды и лечебные грязи Дальнего Востока: справочник. Владивосток: Изд-во ДВФУ, 2017. 220 с.

18. Челнокова Б.И., Иванов Е.М., Гвозденко Т.А. Минеральные воды и лечебные грязи Дальнего Востока: справочник. Владивосток: Изд-во ДВФУ, 2010. 128 с.

19. Шакиров Р.Б., Сырбу Н.С., Обжиров А.И. Распределение гелия и водорода в отложениях и воде на склоне о. Сахалин // Литология и полезные ископаемые. 2016. № 1. C. 68-81. [Shakirov R.B., Syrbu N.S., Obzhirov A.I. Distribution of helium and hydrogen in sediments and water on the Sakhalin slope. Lithology and Mineral Resources. 2016, 51(1): 61-73. https://doi.org/10.1134/s0024490216010065]

20. Штейн М.А. Определение параметров и глубин залегания термальных подземных вод // Tруды СахКНИИ. Южно-Сахалинск: СахКНИИ, 1962. Вып. 12. С. 162-165.

21. Chelnokov G., Zharkov R., Bragin I. Radon monitoring in groundwater and soil gas of Sakhalin Island // J. of Geoscience and Environment Protection. 2015. Vol. 3. P. 48-53. http://dx.doi.org/10.4236/gep.2015.35006

22. Chelnokov G.A., Bragin I.V., Kharitonova N.A. Geochemistry of mineral waters and associated gases of the Sakhalin Island (Far East of Russia) // J. of Hydrology. 2018. Vol. 559. P. 942-953. https://doi.org/10.1016/j.jhydrol.2018.02.049

23. Cicerone R.D., Ebel J.E., Beitton J.A. Systematic compilation of earthquake precursors // Tectonophysics. 2009. № 476. P. 371-396. https://doi.org/10.1016/j.tecto.2009.06.008 
24. Giggenbach W.F. Geothermal solute equilibria. Derivation of $\mathrm{Na}-\mathrm{K}-\mathrm{Mg}-\mathrm{Ca}$ geoindicators // Geochimica et Cosmochimica Acta. 1988. Vol. 52(12). P. 2749-2765. https://doi.org/10.1016/0016-7037(88)90143-3.

25. Kharaka Y.K., Mariner R.H. Chemical geothermometers and their application to formation waters from sedimentary basins // Thermal History of Sedimentary Basins, Methods and Case Histories. New York, 1989. P. 99-117. https://doi.org/10.1007/978-1-4612-3492-0_6 